\title{
Prevalence and Associated Factors of Unintended Pregnancy Among Pregnant Women Attending Antenatal Care Unit at Jimma University Medical Center: A Cross Sectional Study
}

\author{
Niguse Hamba*, Mengistu Ayele and Tinsae Amsalu \\ Department of Biomedical Sciences, Institute of Health, Jimma University, Jimma, Ethiopia \\ *Corresponding author: Niguse Hamba, Department of Biomedical Sciences, Institute of Health, Jimma University, Jimma, \\ Ethiopia
}

\section{ARTICLE INFO}

Received: September 09, 2020

Published: 幽 September 23, 2020

Citation: Niguse Hamba, Mengistu Ayele, Tinsae Amsalu. Prevalence and Associated Factors of Unintended Pregnancy Among Pregnant Women Attending Antenatal Care Unit at Jimma University Medical Center: A Cross Sectional Study. Biomed J Sci \& Tech Res 30(4)-2020. BJSTR. MS.ID.004984.

Keywords: Antenatal Care;Unintended Pregnancy;Modern Contraceptive

\section{ABSTRACT}

Background: Unintended pregnancy is an important public health problem in both developing and developed countries, because of its association with adverse social and health outcomes for mothers, babies, and family as a whole. Unintended pregnancies impose serious health problems to mothers and their infants by causing an unnecessarily high risk of pregnancy-related complications and self-induced abortions. Hence, this study aimed to determine the prevalence of unplanned pregnancy and assess associated factors among pregnant women attending antenatal care at Jimma University Medical Center.In this study a facility-based cross-sectional study design was conducted on pregnant women following antenatal care at Jimma University Medical Center from July 25 to August 20, 2019. A convenience sampling technique was used, and sample size was calculated as 194. The Prevalence of unintended pregnancy was $32.5 \%$ among the study sample; the majority of the unintended pregnancies were miss-timed followed by husband influence. The significant association $(95 \% \mathrm{CI}, \mathrm{p}<0.05)$ was seen between unintended pregnancy and residence, education, and the use of modern contraceptive methods. The prevalence of unintended pregnancy was high in the study area; and programs improving educational status of the partner and knowledge of modern contraceptive methods is demanded.

\section{Introduction}

Unintended pregnancy is defined as a pregnancy which is not wanted and/or not planed at the time of conception [1]. It happens due to different reasons like; not using family planning, failure of contraceptive methods, lack of contraceptive methods, incidental sexual intercourse, including rape, and lack of awareness regarding family planning [2].Unintended pregnancy is an important public health issue in developed and developing countries because of its negative association with the social and health outcomes for both mothers and children. The most common consequence of unintended pregnancy is unsafe abortion [3]. Of the estimated 210 million pregnancies that occur throughout the world each year, about 38 percent are unplanned, out of which 22 percent end in abortion [4].Ninety-five percent of unsafe abortions occur in developing countries [5]. Millions more suffer long-term injuries from often life-threatening complications. In Ethiopia, unsafe abortion is the second common cause of maternal mortality, which accounts for $19.7 \%$ maternal mortality [6]. A national study done in Ethiopia indicates that the number of induced abortions was 620,300 in 2014 [7].

Unintended pregnancy is one of the most critical problems in the public health system that imposes substantial financial and social costs on society. Unintended pregnancy leads to the reduction of quality of life and workforce efficiency, which indicates that unintended pregnancy, affects fertility indicators $[3,8]$.The prevalence of unintended pregnancy is still high worldwide. According to WHO, every year there are around 210 million pregnancies world-wide, out of these pregnancies, $44 \%$ of pregnancies are unintended and around 59\% pregnancies 
ended by abortion. Most of these unintended pregnancies (65 pregnancies per 1000 women) happen in developing countries like Ethiopia $[9,10]$. Different studies done in Ethiopia indicate that the prevalence of unintended pregnancy is $37.8 \%, 36.9 \%, 33.3 \%, 36.5 \%$ and 32.9\% in Addis Ababa [11], Dilla[12], Harar [13], Wellega[14], Debre Markos [15] respectively. There are multiple reasons for unplanned pregnancy, normally non-use of contraception, failure of contraception, unreliable method of contraception, failure of contraception, or rape [16]. Lack of knowledge on sexual and reproductive health is one important that contributed to unplanned pregnancy especially in teenage girls who are commonly left out in the national contraceptive program [17].

Unintended pregnancy is high among women who have lower/ no educational level, single women, women who have low income, women who have multiple sexual partners, unemployed women, women who didn't use family planning, multiparous mothers, young women, women who traveled long time to reach health facility, women who have more children, multi-gravida women, women who are not visited by health professionals, women who discussed with their husband and women who desire fewer children [11-16].Although several international declarations were passed on the problem, many in sub-Saharan Africa are suffering from unwanted pregnancy. In most African countries, abortion remains both unauthorized and unsafe, and the leading cause of maternal death accounted for a global average of $1.3 \%$ of pregnancy-related fatalities [17].This study aimed to assess the prevalence and factors associated with unintended pregnancy among pregnant women attending the antenatal care unit of Jimma university medical centre from July 25 to August 20, 2019.

\section{Methods and Materials}

\section{Study Area and Period}

This study was conducted among pregnant women who were attending the antenatal clinic at Jimma University Medical center (JUMC) from July 25 to August 20, 2019. JUMC is one of the teaching hospitals in Ethiopia, located $345 \mathrm{~km}$ southwest to Addis Ababa.

\section{Study Design}

An institutional-based cross-sectional study was employed.

\section{Source Population}

All pregnant women who attended ANC follow up at JUMC.

\section{Study Population}

All pregnant women who attended ANC follow up at JUMC during the study period.

\section{Inclusion Criteria and Exclusion Criteria}

Inclusion Criteria: Pregnant women who visited the ANC unit during the data collection period and who fulfilled the inclusion criteria were included.
Exclusion criteria: Pregnant women who had a hearing, speech problem, and critically ill were excluded from the study.

\section{Sample Size and Sampling Technique}

The sample size was determined based on the single population proportion formula, with an assumption that $29 \%$ of pregnant women are having unplanned pregnancy in the area [18]. With $5 \%$ margin of error (d) and confidence level of $95 \%(z \alpha / 2=1.96)$. However, because, the total pregnant women attending the health care system were less than 10,000 and we used a correction formula to come up with the final sample size. A convenient sampling technique was used because the pregnant women attending the ANC unite in the area were quite limited and it was almost less than 500 . Hence, Sample size is determined by using the following formula.

$$
\begin{gathered}
n i=\frac{(z \alpha / 2)^{2} p(1-p)}{d^{2}} \\
n i=\frac{(1.96)^{2} 0.29(1-0.29)}{(0.05)^{2}}=316
\end{gathered}
$$

ni $=316$

Where ni- The initial sample size required

P-National prevalence of unplanned pregnancies among woman in reproductive age $=29 \%$ (17)

d- The margin of sampling error tolerated Mostly5\%

$\mathrm{z} \alpha / 2$ - is $95 \%$ of confidence interval

Since our source population is less than 10,000 , which are 500 we use the correction formula as follows.

$$
\begin{gathered}
n f=\frac{n}{1+\frac{n}{N}} \\
n f=\frac{316}{1+\frac{316}{500}}=194
\end{gathered}
$$

Where,

- $\quad \mathrm{nf}=$ final sample size

- $\mathrm{n}=$ total study population which is 316

- $\quad \mathrm{N}=$ source population which is 500 .

\section{Data collection Method and Instrument}

The data was collected by face to face interviews using a structured questionnaire and pre-tested questionnaire. 


\section{Data Quality Control}

The questionnaire was prepared in English for the first time and translated to the local language by a person who does not have any involvement in the study as well as to the discipline. After the translation has over, all necessary modifications were taken place. The data collectors were medical interns and midwifery, both of them were working at the ANC unit in JUMC. To check the validity and reliability of the questionnaire, a pilot study was conducted on $5 \%$ of the actual sample size at JUMC, Oromia region. Moreover, Training was given for the data collectors to minimize technical and observational biases. The questionnaire was modified based on information obtained from pre-test results, as necessary. Data were checked for completeness and consistency before commencing analysis.

\section{Dependent Variable}

- $\quad$ Prevalence of unintended pregnancy

\section{In dependent Variables}

- $\quad$ Age

- $\quad$ Marital status

- $\quad$ Educational status

- $\quad$ Religion

- $\quad$ Ethnicity

- Occupation

- $\quad$ Ever practice of family planning

- $\quad$ Preferred numbers of children by mother

- $\quad$ Husband influence

- $\quad$ Knowledge on contraceptive.

- $\quad$ Residence

\section{Data Processing and Analysis}

The collected data were first checked for completeness, entered, and analyzed by using Statistical Package for Social Science, SPSS (Version 21), chi-square test was used for a test of association between dependent and independent variables and presented in tables and figures.

\section{Results}

\section{Socio-Demographic Characteristics of the Respondents}

From total study participants of 194 women interviewed $62.9 \%$ were Oromo in Ethnicity. From the total study participants $59.2 \%$ were 20-24 years age group at their first marriage and 93.3\% were married in their marital status, $32 \%$ attend secondary education and about $44.8 \%$ were housewife in occupation and about $55.7 \%$ have income below poverty line (Table 1 ).
Table 1: Socio-demographic characteristics of the study participants.

\begin{tabular}{|c|c|c|}
\hline \multicolumn{3}{|c|}{ Socio-demographic Characteristics of the Study Participants } \\
\hline Variable & Frequency(N) & Percentage (\%) \\
\hline \multicolumn{3}{|c|}{ Age Group (yrs) } \\
\hline $15-19$ & 3 & 1.5 \\
\hline $20-24$ & 56 & 28.9 \\
\hline $25-29$ & 95 & 49.0 \\
\hline $30-34$ & 29 & 14.9 \\
\hline $35-45$ & 11 & 5.7 \\
\hline \multicolumn{3}{|c|}{ Marital Status } \\
\hline Married & 181 & 93.3 \\
\hline Single & 2 & 1.0 \\
\hline Widowed & 4 & 2.1 \\
\hline Divorced & 7 & 3.6 \\
\hline \multicolumn{3}{|c|}{ Age at First Marriage } \\
\hline $15-19$ & 11 & 5.7 \\
\hline $20-24$ & 115 & 59.3 \\
\hline $25-29$ & 65 & 33.5 \\
\hline $30-34$ & 3 & 1.5 \\
\hline$>35$ & - & 0 \\
\hline \multicolumn{3}{|c|}{ Residence } \\
\hline Rural & 28 & 14.4 \\
\hline Urban & 166 & 85.6 \\
\hline \multicolumn{3}{|c|}{ Ethnicity } \\
\hline Oromo & 122 & 62.9 \\
\hline Amhara & 49 & 25.3 \\
\hline Tigre & 9 & 4.6 \\
\hline Others & 14 & 7.2 \\
\hline \multicolumn{3}{|c|}{ Religion } \\
\hline Orthodox & 54 & 27.8 \\
\hline Muslim & 98 & 50.5 \\
\hline Protestant & 38 & 19.6 \\
\hline Others & 4 & 2.1 \\
\hline \multicolumn{3}{|c|}{ Educational Level } \\
\hline Illiterate & 21 & 10.8 \\
\hline Can read and write & 32 & 16.5 \\
\hline 1-6 grade & 37 & 19.1 \\
\hline $7-12$ & 62 & 32.0 \\
\hline College/university complete & 42 & 21.6 \\
\hline \multicolumn{3}{|c|}{ Occupational Status } \\
\hline Housewife & 87 & 44.8 \\
\hline Government Employees & 51 & 26.3 \\
\hline Merchant & 44 & 22.7 \\
\hline Others & 12 & 6.2 \\
\hline \multicolumn{3}{|c|}{ Monthly Income in ETB } \\
\hline$<790$ & 108 & 55.7 \\
\hline
\end{tabular}




\begin{tabular}{|c|c|c|}
\hline $790-2805$ & 69 & 35.6 \\
\hline$>2805$ & 17 & 8.7 \\
\hline
\end{tabular}

\section{Knowledge and Practice of the study participants on Modern Contraceptives}

The majority of the study participants $99 \%$ were aware of modern contraceptives. Their numbers for each source of information included: (66.5\%) for health institutions, (32.5\%) for mass media. About $53.1 \%$ knew more than one method of contraceptive. $53.1 \%$ knew at least one advantage of modern contraceptive methods and $45.9 \%$ knew more than one advantage. $68.6 \%$ of study participants had previously used modern contraceptive while $31.4 \%$ had never used any methods of modern contraceptives. Pills were the most frequently used method with $51.5 \%$ followed by Injectable for $38.6 \%$ (Table 2). Out of the total respondents $61(31.4 \%)$ have never used modern contraceptives, for most of them the reason not to use was fear of side effects $(24.6 \%)$ which is followed by religious view(21.3\%) (Figure 1).

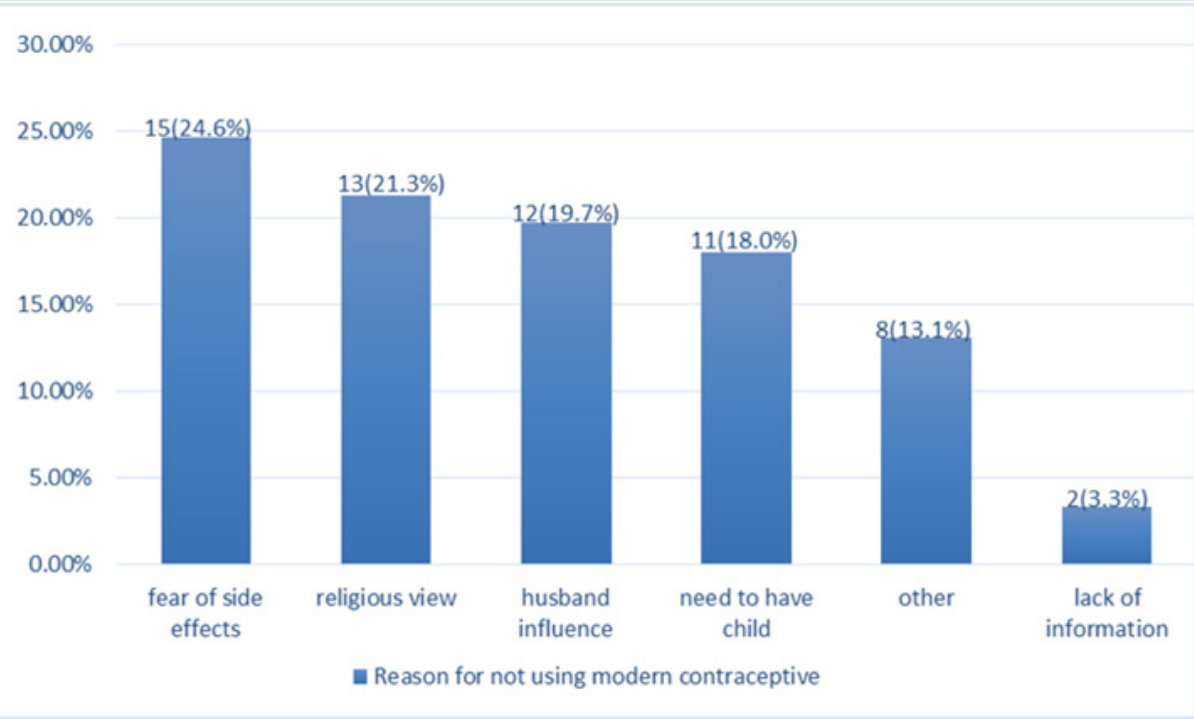

Figure 1: reasons for not using modern contraceptives among study participants.

Table 2: Knowledge and Practice of the study participants on Modern Contraceptives.

\begin{tabular}{|c|c|c|}
\hline \multicolumn{3}{|c|}{ Knowledge and Practice of the Study Participants on Modern Contraceptives } \\
\hline Variable & Frequency & Percentage \\
\hline \multicolumn{3}{|c|}{ Awareness of Modern Contraceptive } \\
\hline Yes & 192 & 99.0 \\
\hline No & 2 & 1.0 \\
\hline \multicolumn{3}{|c|}{ Source Information about Modern Contraceptive } \\
\hline Health workers & 129 & 66.5 \\
\hline Mass media & 63 & 32.5 \\
\hline Others & 2 & 1.0 \\
\hline \multicolumn{3}{|c|}{ Knowledge on Advantages of Modern Contraceptive } \\
\hline Know none & 2 & 1.0 \\
\hline Know at least one & 103 & 53.1 \\
\hline Know greater than one & 89 & 45.9 \\
\hline \multicolumn{3}{|c|}{ Ever used Modern Contraceptive } \\
\hline Yes & 133 & 68.6 \\
\hline No & 61 & 31.4 \\
\hline \multicolumn{3}{|c|}{ Type of Contraceptive Used } \\
\hline Pills & 100 & 51.5 \\
\hline Injectable(Depo-Provera) & 75 & 38.6 \\
\hline Others & 19 & 9.8 \\
\hline
\end{tabular}




\section{Distribution of Respondents by Status of their Current Pregnancy}

Out of the total participants 63(32.5\%) respondents claimed their current pregnancy was unintended. Twenty eight $(44.4 \%)$ claimed that the reason for their unintended pregnancy was that because it was miss timed that is they require the pregnancy in the future, which was followed by husband influence $13(20.6 \%)$ (Figure 2).

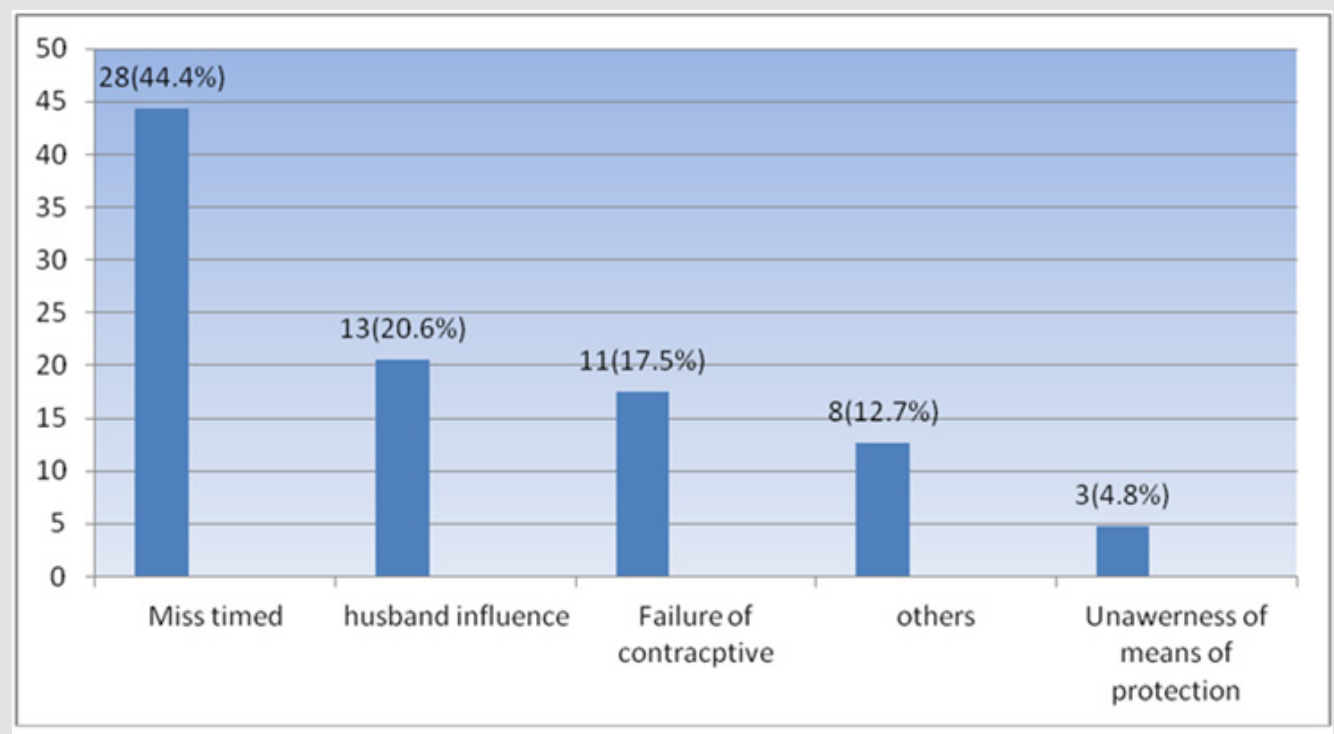

Figure 2: reasons for the occurrence of unplanned pregnancy among study participants.

\section{Perception on Average Number of Children by Study Participants}

As the number of times a woman become pregnant increases, tendency to experience unintended pregnancy increases. Most of the respondents $71(36.6 \%)$ perceived that 3 children in life are enough while only $2(1.0 \%)$ wish to have a single child. Those who claimed their current pregnancy was unplanned only $1(1.6 \%)$ wanted to have five and above children while those with planned current pregnancy17 (13.0\%) of them wish to have (Table 3).

Table 3: Perception on average number of children by study participants.

\begin{tabular}{|c|c|c|c|c|c|c|}
\hline \multirow{2}{*}{ Preferred no of children } & \multicolumn{2}{|c|}{ Intended Pregnancy } & Unintended Pregnancy & \multicolumn{2}{c|}{ Total } \\
\cline { 2 - 7 } & No & \% & No & \% & No & 2 \\
\hline 1 & 0 & 0 & 2 & 3.2 & 38 & 1.0 \\
\hline 2 & 23 & 17.6 & 15 & 23.8 & 71 & 36.6 \\
\hline 3 & 35 & 26.7 & 36 & 14.1 & 65 & 33.5 \\
\hline 4 & 56 & 42.7 & 9 & 1.6 & 18 & 9.3 \\
\hline
\end{tabular}

\section{Factors associated with Unplanned Pregnancy Status}

The chi-square analysis indicated that income status among study participants (P-value $=0.2209$ ), and religion ( $p$-value $=0.3629)$ were found not to be significant of association with unintended pregnancy; whereas residence $(p$-value $=0.00001)$ modern contraceptive use ( $p$-value $=0.0175)$, Educational status ( $p$-value $=0.0130$ ) were found to be significant of association with unintended pregnancy.

\section{Discussion}

The prevalence of unintended pregnancy in this study was $32.5 \%$ which is consistent with similar studies conducted in Harar
[13], Debre Markos[15] 33.3\%, and 32.9\% respectively and higher than a study done in Kersa(27.9\%) [19] and Gelemseo General Hospital (27.1\%) [20].The difference might be due to the difference in the source population, sample size where the present study focused only on pregnant women attending ANC at the health institution. However, the finding of this study is lower than studies done in Addis Ababa (37.8\%) [11], Dilla (36.9\%) [12], Wellega (36.5\%) [14]. This difference may be due to different reasons like study design difference in in sample size, socio-cultural difference, time variation, demographic differences between the current study and the previous studies. For instance, a study done in Wellega is a community-based study design which assessed all pregnant 
women including who had no antenatal visit. So, the difference between the current study and previous Wellega study may be study design difference. In addition to this, the difference may be due to cultural and religious difference. Globally the prevalence of unintended pregnancy is 38\% [21]. which is larger than the finding in this study. In Sub-Saharan Africa (SSA) 39\% of pregnancies are unintended, ranges from 30\% in Western Africa to 59\% in Southern Africa in 2014 [22].

The current study showed that residence is significantly associated with an unintended pregnancy $(\mathrm{p}=0.00001)$, these findings were in line with a study in Khartoum state Sudan [23] Wollega[14].This is because women who live in rural areas have less contraceptive usage and husband influence is more common in women who reside in rural areas than that of urban. Study in Pakistan also showed that the women who had at least one son were almost three times more likely to report their recent pregnancies unintended compared to those who did not have a son [24]. Also, in a study done in Vietnam, increased number of live sons was positively associated with unintended pregnancy [25]. This implies that, culturally, male child preference is common in these countries, particularly in rural areas. The women who had a live male child may have been interested in preventing pregnancy for the sake of spacing or may no longer desire fertility, but with limited contraceptive use, they may experience an unintended pregnancy. In addition, urban women are almost three times more likely than rural women to receive ANC from a skilled provider.The study also has revealed that short-acting contraceptives (Injectable Depo Provera and oral contraceptive pills) were highly used by the respondents.

Further, literature supported the findings of this study, where these short-acting contraceptives possess potential problems with compliance and convenience such as missing the doses resulting in higher unintended pregnancy rates. As was reported 38.6\% of respondents use Injectable Depo Provera, followed by $51.5 \%$ oral contraceptive pills which were comparable with the national figure which is $77.8 \%$ of those who use modern contraceptives use injectable one Ethiopia Demographic and Health Survey 2011 [18]. Most of the respondents use short-acting contraceptives because they thought it is easy for administration, easy to regain their productivity, and more comfortable which needs extensive awareness creation. According to the respondents in this study, those who do not use modern contraceptives most of them(24.6\%) were because of fear of side effects which was similar to the study in Ganji[26]. There is a probability of missing doses in short-acting contraceptive use; this is probably why failure contraceptive methods have contributed to the occurrence of an unplanned pregnancy.In this study even though the awareness of family planning is high (99\%) of respondents, $44.4 \%$ was miss-timed which was analogous with the study finding in Khartoum state Sudan [27] and Ganji[26].
But only $68.6 \%$ of them have ever practiced modern contraceptives. The most frequent reason mentioned by the participants in this study to refer to the pregnancy as unplanned was miss-timed, which means they want to become pregnant in the near or late future time. Furthermore, in this study, unintended pregnancy was associated with There is a direct relationship between a woman's education level and whether she is likely to receive ANC from a skilled provider.

\section{Conclusion}

This finding concluded that the prevalence of unintended pregnancy is relatively high in the study area. Educational status, residence, and religion were the most important predictor variables of unintended pregnancy. The social-cultural and economic positions of women in society as well as an influence by her husband were also contributed to unintended pregnancy Reducing the prevalence of unintended pregnancy especially in the rural area is recommended.

\section{Limitations}

As this is a cross-sectional study, the associations observed may not be causal enough and since this study is institution based, it may suffer from lack of generalizability.

\section{Ethical Consideration}

Before the data collection letter of permission was taken from Jimma University, Institute of Health to JUMC and Ethical clearance was obtained from Jimma University Institutional Review Board. The objective of the study was explained to the study participants, privacy maintenance and confidentiality was ensured. Furthermore, the study participants' involvement in the study was based on their willingness.

\section{Competing Interests}

The authors declare that they have no competing interests.

\section{References}

1. (2015) World Health Organization. Unintended pregnancy; Improving maternal and child health. World Health Organization.

2. (2015) American Pregnancy Association. Unintended pregnancy. USA; American pregnancy Association.

3. Mansureh Y, Abolghasem P, Arezoo P, Fatemeh AI (2015) Unintended Pregnancy and Its Adverse Social and Economic Consequences on Health System: A Narrative Review Article. Iran J Public Health 44(1): 12-21.

4. Amin F, Howden P, Peyman NA (2009) Risk Factors of Unplanned Pregnancies in a Group of Iranian and New Zealander Women. European Journal of Scientific Research 26(1): 108-121.

5. (2010) World Health Organization. Global and Regional estimates of the incidence of unsafe abortion and associated mortality. ( $5^{\text {th }}$ Edn.).

6. Tessema AG, Caroline OLe, Melaku YA, Misganaw A, Woldie AS Sintayeh, et al. (2017) Trends and causes of maternal mortality in Ethiopia during 1990-2013: Findings from the Global Burden of Diseases study 2013. BMC Public Health 17: 160.

7. Ann MM, Yirgu Gebrehiwot, Tamara F, Wado YD, Akinrinola B, et al. (2016) The Estimated Incidence of Induced Abortion in Ethiopia, 2014: 
Changes in the Provision of Services Since 2008. Int Perspect Sex Reprod Health 42(3): 111-120.

8. Caitlin G, Loren D, Diana GF, Eleanor BSz (2016) Side Effects, Physical Health Consequences, and Mortality Associated with Abortion and Birth after an Unwanted Pregnancy. Women's Health Issues 26(1): 155-159.

9. (2017) World Health Organization. World Malaria report 2017. Geneva: World Health Organization.

10. Jonathan B, Anna P, leontine A (2018) Global, regional, and subregional trends in unintended pregnancy and its outcomes from 1990 to 2014 Estimates from a Bayesian Hierarchical Model. Lancet Global Health.

11. Mulatu T, Cherie A, Negesa L (2017) Prevalence of Unwanted Pregnancy and Associated Factors among Women in Reproductive Age Groups at Selected Health Facilities in Addis Ababa, Ethiopia. J Women's Health Care 6: 392.

12. Feyisso M, Girma A, Yimam H, Hailu S (2017) Magnitude of Unintended Pregnancy and its Determinants among Pregnant Women Visiting Dilla University Referral Hospital, South Ethiopia. J Women's Health Care 6: 388.

13. Worku S, Fantahun M (2006) Unintended pregnancy and induced abortion in a town with accessible family planning services: The case of Harar in eastern Ethiopia. Ethiop J Health Dev 20(2).

14. Teshome TF, Hailu AG, Teklehaymanot NA (2014) Prevalence of Unintended Pregnancy and Associated Factors among Married Pregnant Women in Ganji Woreda, West Wollega Oromia Region, Ethiopia. Science Journal of Public Health 2(2): 92-101.

15. Kibret A, Bayu HA, Merga M (2015) Prevalence of Unintended Pregnancy and Associated Factors among Pregnant Women Attending Antenatal Clinics in Debre-markos Town, North West Ethiopia 2012. J Women's Health Care 4: 232

16. (2009) World Health organization. word health statistics.

17. (2011) World health organization. Unsafe abortion Global and regional estimates of the incidence of unsafe abortion and associated mortality in 2010, (4 ${ }^{\text {th }}$ Edn.). WHO, Geneva, Switzerland.

\section{ISSN: 2574-1241}

DOI: $10.26717 /$ BJSTR.2020.30.004984

Niguse Hamba. Biomed J Sci \& Tech Res

CC (P) This work is licensed under Creative Commons Attribution 4.0 License

Submission Link: https://biomedres.us/submit-manuscript.php
18. (2012) Ethiopia Demographic and Health Survey. Addis Ababa, Ethiopia and Calverton, Maryland, USA: Central Statistical Agency and ICF International.

19. Assefa N, Berhane Ye, Worku A (2012) Predictors of unintended pregnancy in Kersa, Eastern Ethiopia, 2010. Reproductive Health 9: 1.

20. Mohammed F, Musa At, Amano A (2016) Prevalence and determinants of unintended pregnancy among pregnantwoman attending ANC at Gelemso General Hospital, Oromiya Region, East Ethiopia: A facility based cross-sectional study. BMC Women's Health 16: 56.

21. Wulf D (2009) The Alan Guttmacher Institute, Sharing Responsibility: Women, Society and Abortion Worldwide. AGI, New York, USA.

22. Singh S, Darroch JE, Ashford LS, Vlassoff M (2014) Adding It Up: The Costs and Benefits of Investing in Family Planning and Maternal and Newborn Health. New York: Guttmacher Institute and United Nations Population Fund.

23. Huacher D, Mavranezouli I, Mc Ginn E (2008) Unintended pregnancy in sub-Saharan Africa: Magnitude of the problem and potential role of contraceptive implants to alleviate it. Contraception. Elsevier science Inc 78(1): 73-78.

24. Ali S, Abrejo F (2017) The relationship between contraceptive use and unintended pregnancies among married women in Thatta District, $\hat{A}$ Pakistan. Journal of Midwifery and Reproductive Health 5(3): 950- 957.

25. Sathar Z, Singh S, Rashida G, Shah Z, Niazi R (2014) Induced abortions and unintended pregnancies in Pakistan. Studies in Family Planning 45(4): 471-491.

26. Fetene $\mathrm{T}$ Teshome, Abebe Gebremariam Hailu, Aaderajew Nigussie Teklehaymanot (2014) Prevalence of unintended pregnancy and associated factors among married pregnant women in Ganji woreda, west Wollega Oromia region, Ethiopia. Science Journal of Public Health 2(2).

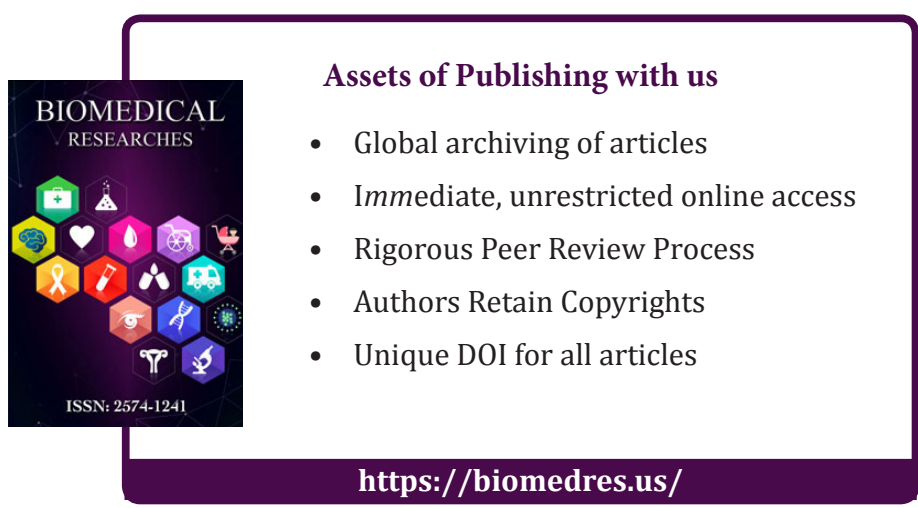

